Pl. Syst. Evol. 265: 165-177 (2007)

Plant Systematics

DOI 10.1007/s00606-007-0519-0

and Evolution

Printed in The Netherlands

\title{
Morphological systematics of Serapias L. (Orchidaceae) in Southwest Europe
}

\author{
C. Venhuis, P. Venhuis, J. G. B. Oostermeijer, and P. H. van Tienderen \\ Institute for Biodiversity and Ecosystem Dynamics, Universiteit van Amsterdam, Amsterdam, \\ The Netherlands
}

Received January 27, 2006; accepted January 18, 2007

Published online: April 30, 2007

(C) Springer-Verlag 2007

\begin{abstract}
We measured morphological characters and relative DNA contents to assess variation and phylogenetic relationships among Serapias species in three populations of each of the 10 putative taxa that occur in Southwest Europe. DNA contents indicated diploidy for most species, except for tetraploid $S$. lingua and hexaploid S. olbia. Multivariate (discriminant) analyses yielded two main groups: a smallflowered S. parviflora group and a large-flowered $S$. vomeracea group. Within the $S$. parviflora group, $S$. elsae should be considered a large-flowered variation of $S$. strictiflora. The geographically disjunct $S$. gregaria and S. strictiflora are probably different taxa. In the $S$. vomeracea group, analyses suggest that $S$. neglecta and $S$. cordigera are closely related. Serapias cordigera from the southwestern coast of the Iberian Peninsula is probably a subspecies, $S$. perez-chiscanoi was separated from all other species and $S$. occidentalis was morphologically intermediate between $S$. cordigera and $S$. vomeracea, suggesting a hybrid origin, with the latter two taxa as parents.
\end{abstract}

Key words: Mediterranean, morphology, orchids, phylogeny, self-pollination, systematics, taxonomy.

The number of recognised species in the orchid genus Serapias L. varies strongly among authors. Delforge (2002) recognised 26 species, while Sundermann (1980) only mentioned three. The distribution is predominantly Mediterranean. Its range extends from the Azores and the Canaries in the west to the Caucasus in the east, and as far north as Brittany (France) (Gölz and Reinhard 1980; Perez Chiscano et al. 1991; Delforge 1995, 2002). The genus is considered monophyletic, based on genetic (Pridgeon et al. 1997; Bateman et al. 1997, 2003) and morphological differences (Delforge 1995, 2002). Serapias is represented in southwest Europe (Iberian Peninsula and southern France) by ten species (Delforge 2002) (Table 1). Taxa within the genus are morphologically still poorly defined. Systematic studies based on morphology have utilized both quantitative and qualitative characters (e.g. Baumann and Künkele 1989, Martine and Gerbaud 1998). However, a detailed study of the morphological variation, using multivariate analysis of many traits, has not previously been undertaken.

Serapias is also poorly studied at the molecular genetic level. Aceto et al. (1999) concluded that, although variation for floral characters and molecular markers corresponded closely, the phylogenetic patterns within the genus could not be resolved with 
the molecular markers used (ITS). Pellegrino et al. (2001) isolated and characterised microsatellite loci from $S$. vomeracea that could prove applicable to all Serapias species.

The aims of the present study are: (1) to determine the taxonomic status of the Serapias species, as described by Delforge (2002, 2004), from the Iberian Peninsula and southern France on the basis of a large number of morphological characters, (2) to determine variation in quantitative and qualitative characters within and among the putative taxa, (3) to determine the relative DNA content and thereby infer information on their ploidy level, and (4) to explore the phylogenetic relationships among the species based on morphological characters.

\section{Materials and methods}

Approach. We sampled three populations, each counting 25 specimens, of all ten presently recognised taxa by Delforge $(2002,2004)$ as occurring in Spain, Portugal and southern France. In addition, we sampled plants of the recently described $S$. occidentalis C. Venhuis \& P. Venhuis (Venhuis et al. 2006). So, in total 75 specimens per taxon have been sampled.

Table 1. Groups and species recognised in the genus Serapias in southwest Europe by Delforge (2002)

\begin{tabular}{ll}
\hline Groups & Species \\
\hline S. parviflora group & S. parviflora Parlatore \\
S. vomeracea group & S. vomeracea (Burman) \\
& Briquet \\
& S. cordigera L. \\
& S. neglecta De Notaris \\
& S. perez-chiscanoi Acedo \\
S. lingua group & S. lingua L. \\
& S. olbia Verguin \\
& S. gregaria Godfery \\
& S. strictiflora Welwitsch \\
& ex da Veiga \\
& S. elsae Delforge \\
\hline
\end{tabular}

Morphology. A total of 23 vegetative and floral characters were recorded for each specimen. Fifteen of these characters were measured quantitatively (Table 2) and eight qualitatively (epichile -curvation, -hair distribution, -shape, -position and lamellae position, hood postion, petal shape and the bract/hood length ratio), using pre-made categorical verification lists to avoid subjective and gradual changes over time in scoring procedures.

Multivariate statistical analyses. To determine whether the measured morphological characters could significantly discriminate among the taxa presented by Delforge (2002) we used a Discriminant Analysis. This approach maximises the variance among relative to within predefined groups and tests which of the measured characters contributes significantly to the discriminating functions.

DNA content. We sampled leaves of five plants per population, which were analysed with a Partec Flow Cytometer, following the standard preparation and staining procedures. Trout fluorescent erythrocytes were added to the analysed solution as a reference. The outcomes of the analyses were plotted in a frequency histogram. The histogram displays relative fluorescence intensity versus the number of cells. The results have been compared with ploidy levels based on previous chromosome counts on $S$. perez-chiscanoi (diploid, $2 \mathrm{n}=36$ ) by Perez Chiscano (1988) and on S. lingua (tetraploid, $2 \mathrm{n}=72$ ) by D'Emerico et al. (1998).

Phylogeny. To explore the putative phylogenetic relationships among the study species, we used the computer program Phylip 3.61. Within Phylip, we used the procedure CONTML, which was especially designed for continuous characters and employs the Maximum Likelihood method, based on the Brownian motion model. The analysis was based on averaged floral dimensions (length and width of bracts, hypochile and epichile, length of sepals and number of flowers) and on four qualitative flower characters (epichile position, shape of the lamellae, petal shape, and bract to hood length ratio). We used Anacamptis palustris (Jacq.) R.M. Bateman, Pridgeon and M.W. Chase, which is closest related to the genus Serapias (Aceto et al. 1999, Bateman et al. 2003), as the outgroup in our analyses. However, the long branch length subtending the outgroup makes the rooting of the tree not very reliable. It was sufficient to use one outgroup only, because Serapias was already known to be monophyletic. 
Table 2. Pooled within-group correlations between the quantitative morphological characters and standardized canonical discriminant functions for the main analysis on all species, and the two separate analyses on each of the two main groups yielded by the first analysis. The largest absolute correlations between each variable and any discriminant function are indicated in bold.

\begin{tabular}{|c|c|c|c|c|c|c|c|c|}
\hline \multirow{4}{*}{$\begin{array}{l}\text { Eigenvalue } \\
\% \text { Variance Explained }\end{array}$} & \multicolumn{3}{|c|}{ Analysis on all species } & \multicolumn{2}{|c|}{$\begin{array}{l}\text { Subanalysis } \\
\text { S. parviflora group }\end{array}$} & \multicolumn{3}{|c|}{$\begin{array}{l}\text { Subanalysis } \\
\text { S. vomeracea group }\end{array}$} \\
\hline & DA1 & DA2 & DA3 & DA1 & DA2 & DA1 & $\mathrm{DA} 2$ & DA3 \\
\hline & 7.01 & 2.71 & 1.32 & 2.90 & 1.68 & 4.45 & 2.94 & 1.33 \\
\hline & 54.5 & 21.1 & 10.2 & 46.9 & 27.2 & 48.4 & 32.0 & 14.4 \\
\hline Epichile width & 0.847 & 0.047 & 0.208 & 0.601 & -0.091 & -0.260 & 0.538 & 0.355 \\
\hline Hypochile width & 0.607 & -0.140 & 0.080 & 0.407 & -0.109 & -0.392 & 0.350 & 0.171 \\
\hline Epichile length & $\mathbf{0 . 5 3 5}$ & -0.237 & 0.335 & 0.486 & 0.272 & -0.305 & 0.092 & 0.122 \\
\hline Hypochile length & 0.296 & -0.576 & 0.364 & 0.429 & 0.544 & -0.609 & -0.068 & 0.362 \\
\hline Bract width & 0.189 & -0.023 & 0.672 & -0.075 & 0.420 & -0.026 & -0.276 & 0.261 \\
\hline Plant height & 0.003 & 0.171 & 0.646 & -0.179 & 0.464 & 0.215 & -0.140 & 0.516 \\
\hline Bract length & 0.139 & 0.040 & 0.558 & -0.164 & 0.327 & 0.020 & -0.156 & 0.201 \\
\hline Sepal length & 0.355 & -0.105 & 0.499 & 0.227 & 0.303 & -0.121 & -0.062 & 0.315 \\
\hline Mean length rosette leaves & 0.049 & 0.156 & 0.471 & -0.184 & 0.300 & 0.132 & -0.010 & 0.520 \\
\hline Number of rosette leaves & 0.076 & 0.248 & 0.368 & -0.065 & 0.147 & 0.241 & 0.047 & 0.353 \\
\hline Number of flowers & 0.151 & 0.272 & 0.215 & -0.186 & -0.028 & 0.188 & 0.047 & 0.036 \\
\hline Number of stem leaves & 0.094 & 0.289 & 0.198 & -0.100 & 0.021 & 0.304 & 0.054 & 0.024 \\
\hline Mean width rosette leaves & 0.109 & 0.047 & 0.262 & -0.191 & 0.030 & -0.031 & -0.141 & 0.056 \\
\hline Ovary length & 0.016 & 0.041 & 0.312 & -0.166 & 0.288 & 0.010 & -0.044 & 0.179 \\
\hline Petal length & 0.345 & -0.133 & 0.446 & 0.228 & 0.267 & -0.151 & -0.078 & 0.248 \\
\hline
\end{tabular}

\section{Results}

Morphology: qualitative characters. Most qualitative morphological character states were constant within populations and species. The bract length to hood length ratio, however, varied strongly within and between populations and species. It was always less than 1 (i.e. bract shorter than the hood) for S. lingua, and varied within all other sampled populations. On average, most species were characterised by bracts that were shorter than the hood. Exceptions were two populations of $S$. parviflora from the Iberian Peninsula, all populations of $S$. vomeracea subsp. vomeracea, and two populations of $S$. strictiflora. The shape and position of the lamellae were constant within all species. Serapias parviflora, S. perez-chiscanoi, $S$. vomeracea subsp. vomeracea and $S$. neglecta had (almost) parallel and rather widely spaced lamellae (Fig. 1). Lamellae of S. occidentalis were almost parallel, but were placed much closer together. Serapias cordigera had divergent lamellae, while $S$. lingua had an entire or emarginated swelling. The stigmatic surface of $S$. olbia, S. gregaria, S. strictiflora and $S$. elsae contained a deeply grooved swelling, which was slightly variable in shape and serration (Fig. 1).

Morphology: discriminant analyses. Discriminant analyses on morphometric data showed separation between two main groups:

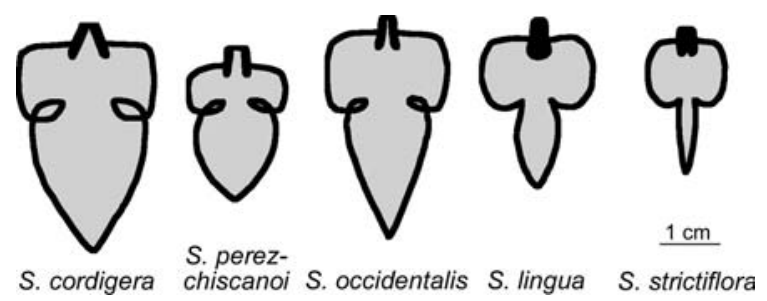

Fig. 1. Labellum and lamellae shapes of S. cordigera, $S$. perez-chiscanoi, S. occidentalis, S. lingua and $S$. strictiflora based on averaged measurements. The lamellae are positioned at the centre of the labellum on the upper part of the hypochile 
one comprising S. parviflora, S. lingua, S. olbia, $S$. gregaria, $S$. strictiflora, and $S$. elsae $(=S$. parviflora group), and the other including $S$. vomeracea subsp. vomeracea, S. neglecta, S. occidentalis, S. cordigera and $S$. perez-chiscanoi ( $=S$. vomeracea group) (Fig. 2a, b). Three functions, each with an Eigenvalue exceeding one, together explained $85.8 \%$ of the total morphological variance (Table 2). The first function distinguished the groups on the width of the epichile and hypochile, and the length of the epichile (Table 2). The second function characterised the length of the hypochile, while the length and width of the bracts, the length of the sepals and plant height contributed to the third function (Table 2).

Discriminant analysis of the $S$. parviflora group separately showed a close resemblance between $S$. gregaria and $S$. lingua, and between S. strictiflora and S. elsae (Fig. 3a). To further clarify the morphological differentiation of $S$. olbia, we performed a discriminant analysis on species from the $S$. vomeracea group from southern France, combined with $S$. olbia and $S$. lingua. This analysis showed that $S$. olbia is similar to $S$. vomeracea subsp. vomeracea and $S$. lingua (Figure not shown).

Separate discriminant analysis on the $S$. vomeracea group showed morphological differentiation between $S$. cordigera and $S$. neglecta and between $S$. vomeracea subsp. vomeracea and S. occidentalis for the first and third function, and a close resemblance for the second function (Fig. 3b, c). Serapias perezchiscanoi was clearly separated from the other taxa for most functions (Figs. 2a, 3b, c).

Relative DNA content. Analyses of all species resulted in two or three fluorescence peaks due to endoreduplication; the first peak was considered to represent the unreplicated nuclear DNA contents. The trout reference DNA showed a DAPI fluorescence peak around 20 partec, the first significant fluorescence peak of $S$. perez-chiscanoi was found at approximately 50 partec, and the first significant fluorescence peak of $S$. lingua at around 100 partec. Serapias parviflora, S. vomeracea subsp. vomeracea, $S$. neglecta, S. cordigera,
S. occidentalis, S. gregaria, S. strictiflora and $S$. elsae all showed fluorescence peaks around 50 partec, whereas $S$. olbia had the first significant fluorescence peak around 150 partec. Interpretation of the fluorescence peaks, combined with the previously known ploidy levels and chromosome numbers of $S$. perez-chiscanoi (diploid, $2 \mathrm{n}=36$ ) and $S$. lingua (tetraploid, $2 \mathrm{n}$ $=72$ ), suggests that $S$. parviflora, $S$. vomeracea subsp. vomeracea, $S$. neglecta, $S$. occidentalis, $S$. cordigera, S. perez-chiscanoi, S. gregaria, $S$. strictiflora and $S$. elsae are all diploid, with $2 \mathrm{n}=36$, S. lingua is a tetraploid with presumably $2 \mathrm{n}=72$, and $S$. olbia is a hexaploid, with presumably $2 \mathrm{n}=108$.

Phylogeny. The morphological analyses give some insight into the possible evolutionary relationships among the studied Serapias species. Phylogenetic analysis of the morphological data-matrix resulted in two groups, suggesting that two distinct lineages have evolved within the genus (Fig. 4). One group contains the large-flowered species (S. vomeracea group) and the other four small-flowered species ( $S$. parviflora group). Serapias lingua and $S$. olbia are placed near to the largeflowered group, most likely due to their relatively large flowers. Based on this tree, $S$. cordigera and $S$. neglecta and both $S$. strictiflora and $S$. elsae are morphologically highly similar. According to the analysis, S. occidentalis is intermediate between $S$. vomeracea subsp. vomeracea and S. cordigera.

\section{Discussion}

Grouping. The groups that emerged from the discriminant analyses (Fig. 2a, b) and the phylogenetic reconstruction based on the morphological characters (Fig. 4) were not concordant with the taxonomic classifications postulated by Baumann and Künkele (1989) and Delforge $(1995,2002)$. Instead of three groups (a S. parviflora group, a $S$. vomeracea group and a $S$. lingua group: Delforge $1995,2002)$ or four groups (Baumann and Künkele 1989), only two main groups could be distinguished: a $S$. parviflora group and a 

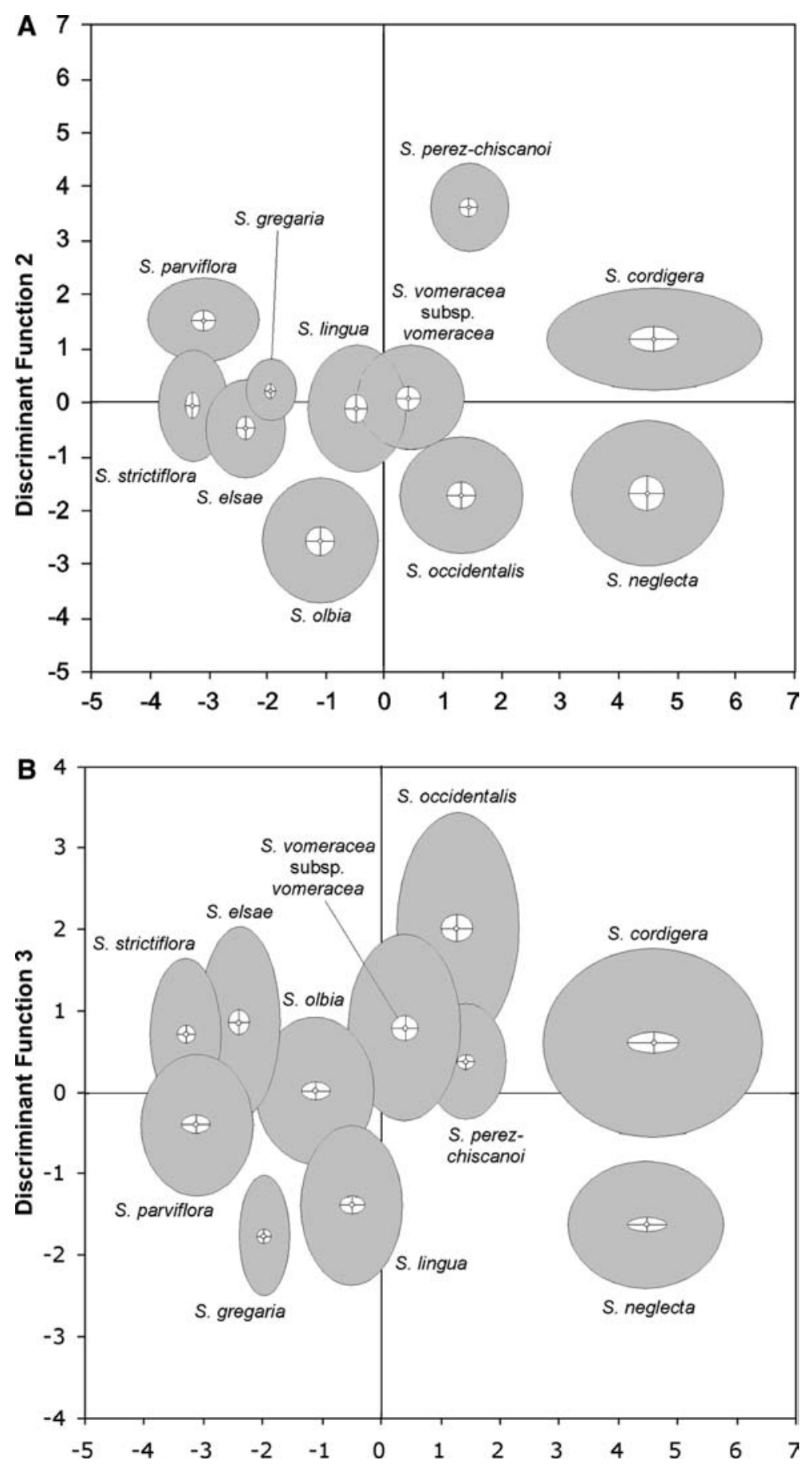

Fig. 2. Discriminant analyses with $95 \%$ confidence intervals (inner circle) and standard deviation (outer, grey circles) of: A all sampled Serapias species, first and second discriminant functions; B all sampled Serapias species, first and third discriminant functions

S. vomeracea group. These groups were predominantly separated on the basis of the epichile width (Table 2).
Below, we discuss the possible relationships between the different taxa based on our results. 

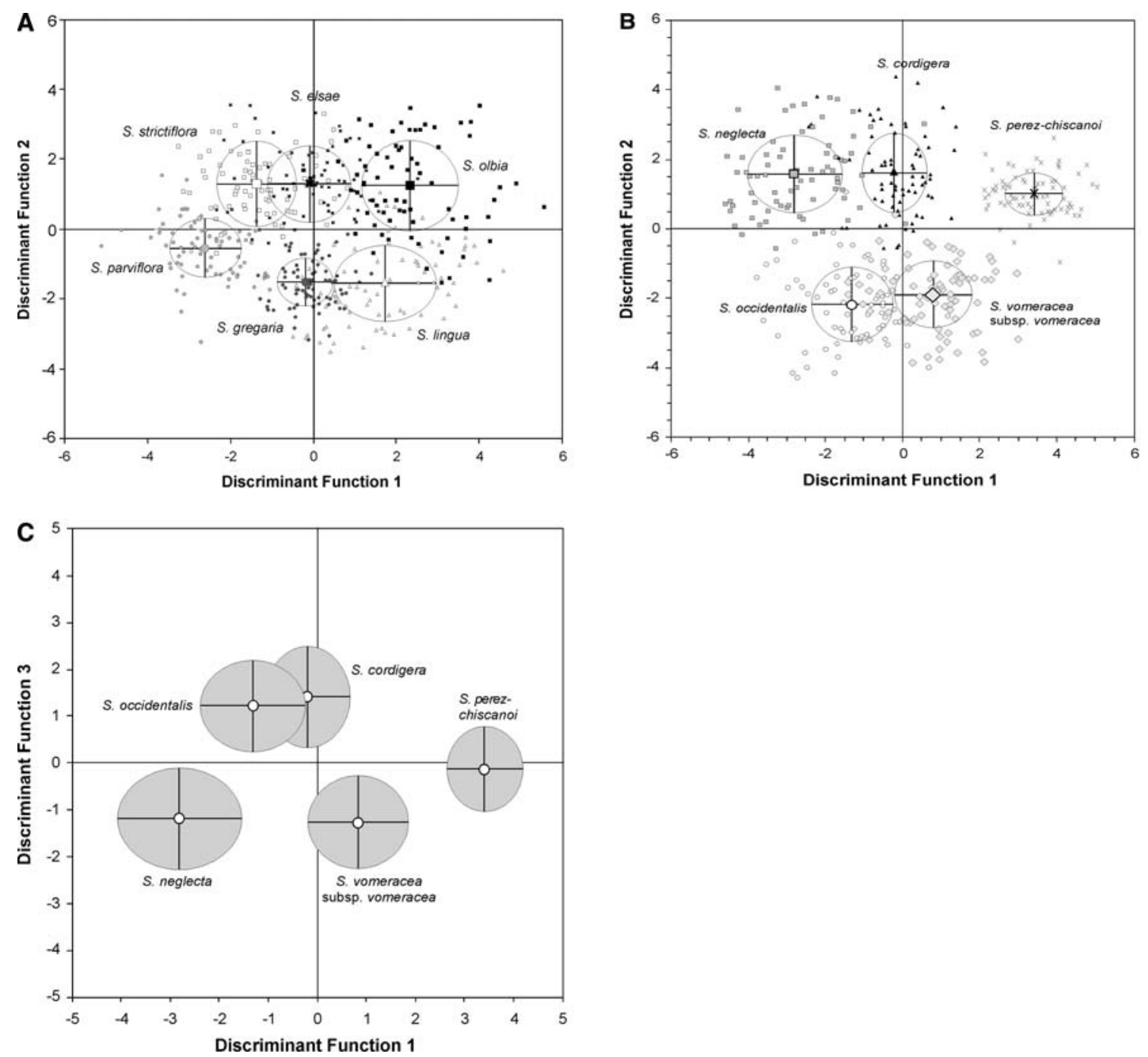

Fig. 3. Separate discriminant analyses of the two main groups, showing the scatter of the original samples and the standard deviation (indicated by the circles around the centroids of each species, centroids have the same symbol as the sample points) A of the $S$. parviflora group; B of the $S$. vomeracea group, first and second discriminant functions; $\mathbf{C}$ the $S$. vomeracea group, first and third discriminant functions (only centroids with standard deviations (grey circles) shown)

S. parviflora group: $S$. lingua and $S$. parviflora. Bateman et al. (2003) suggested that $S$. lingua could be an autopolyploid derivative of $S$. parviflora. This hypothesis is not supported by our discriminant analyses (Fig. 2a, 3a). $S$. parviflora differs from $S$. lingua for two disciminant functions and has two parallel lamellae on the base of the hypochile, whereas $S$. lingua generally has a single swelling (Fig. 1). More likely candidates are S. stricti- flora (which differs in only one discriminant function, and also has a single (albeit grooved) swelling on the base of the hypochile), and $S$. vomeracea (largely similar for all discriminant functions, Fig. 2a, but with two lamellae). Serapias olbia, S. strictiflora, S. gregaria and $S$. elsae belong to the $S$. parviflora group, in addition to $S$. lingua.

S. olbia. On the basis of the observed relative DNA contents, we conclude that 


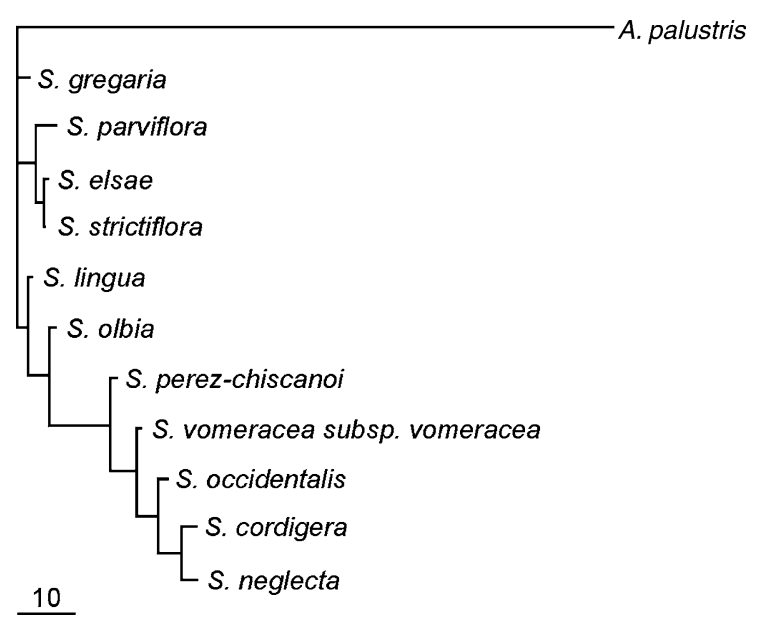

Fig. 4. Phylogenetic relationships between all sampled Serapias species inferred as by the CONTML algorithm (PHYLIP 3.61). Two groups can be distinguished: a $S$. parviflora group and a $S$. vomeracea group. Serapias lingua and S. olbia in between these groups, but closer to the $S$. vomeracea group, due to their relatively large flowers. Horizontal bar indicates the scaling for the branch lengths (the expected accumulated variance under the assumed model of independent, 'Brownian' divergence)

S. olbia has a polyploid background, and - to our knowledge - is the first hexaploid Serapias species. It probably has evolved by hybridization between tetraploid S. lingua and another, diploid, parental species. Baumann and Künkele (1989) and Delforge $(1995,2002)$ suggested $S$. cordigera as the diploid parent. According to Delforge (1995, 2002), S. olbia is a species with primitive characters, which is basal to the two main evolutionary branches, with $S$. lingua on one side and $S$. cordigera on the other. However, S. cordigera and S. olbia are morphologically dissimilar, except for the red-purple epichile colour. Our morphometric analysis rather suggests $S$. vomeracea subsp. vomeracea as the diploid parent species of S. olbia (figure not shown), in concordance with Schlechter (1923).

S. strictiflora and $S$. gregaria. Delforge (1995, 2002) considered S. strictiflora and $S$. gregaria as true species, that probably both evolved from hybrids between tetraploid $S$. lingua and diploid $S$. parviflora. Interpretation of the relative DNA content suggests that both species are diploid, which therefore excludes the tetraploid S. lingua as a likely parent. Martine and Gerbaud (1998) argued that $S$. strictiflora and $S$. gregaria should be considered conspecific, but their analyses used only three floral characters. Our discriminant analyses (Fig. 3a) show that $S$. strictiflora differs from $S$. gregaria in plant height (212 versus $113 \mathrm{~mm}$, respectively), hypochile length (9.1 versus $7.8 \mathrm{~mm}$ ), sepal length (19.8 and $14.8 \mathrm{~mm})$ and epichile width (4.7 versus $5.4 \mathrm{~mm}$ ). The analyses show that $S$. gregaria more closely resembles $S$. lingua and that $S$. strictiflora is more similar to $S$. parviflora. Our phylogenetic analyses also show that $S$. strictiflora is very similar to $S$. parviflora, whereas $S$. gregaria is placed closer to $S$. lingua. No single character, however, discriminates one species from the other. Separate distributions ( $S$. gregaria is restricted to southern France, whereas $S$. strictiflora is restricted to the southwest part of the Iberian Peninsula and regions of northern Africa), combined with morphometric and phylogenetic analyses, lead us to hypothesize that these two species presumably originated independently. Their treatment by Kreutz (2004) as $S$. strictiflora subsp. strictiflora and as $S$. strictiflora subsp. gregaria therefore seems premature.

S. elsae. Maire and Stephenson (1930) described S. stenopetala from Algeria, which was renamed $S$. lingua subsp. stenopetala by Maire and Weiller (1959). Delforge (1995, 2002) also recognised this taxon from the southwestern part of the Iberian Peninsula, but under the name $S$. stenopetala. He described plants as having pale flowers, bracts exceeding the hood and a grooved stigmatic surface. Based on his field observations, he concluded that it is not a variety of $S$. lingua and that it has evolved into a species with deviant characters, rather than an occasional hybrid. Baumann and Künkele (1989), Venhuis et al. (2004), Presser (pers. comm., 2004) and Tyteca (pers. comm., 2004) have all questioned the taxonomic status of this species. On the basis of recent photos of S. lingua subsp. stenopetela 
from Algeria, Delforge (2004) also recognised that the plants from Algeria were not morphologically similar to $S$. stenopetala from the Iberian Peninsula, and hence described the latter as a distinct species, S. elsae.

Our observations on plants of $S$. elsae from the Iberian Peninsula show that: (1) the majority of the flowers were red, and only rarely pale, (2) in each analysed population only a few plants had bracts that exceeded the hood, and (3) in all populations of S. elsae, the majority of specimens closely resembled $S$. strictiflora. Delforge (2004) hypothesised that $S$. elsae originated from a hybrid between $S$. strictiflora and $S$. lingua. Our analysis of the relative DNA content showed that $S$. elsae is most likely diploid, and therefore could not have originated from hybridisation between tetraploid S. lingua and diploid S. strictiflora. In addition, our morphometric and phylogenetic analyses showed that $S$. elsae more closely resembled $S$. strictiflora than $S$. lingua (Figs. 2a, b, 3a, 4). We also found that all qualitative characters corresponded with $S$. strictiflora. On this basis, we conclude that $S$. elsae is only a large-flowered variant of $S$. strictiflora, which we propose to name $S$. strictiflora var. elsae. We did not find this taxon in southern Andalusia, where S. strictiflora appears to grow in pure populations, but only in the Algarve up to Mafra and further inland to Evora, and the westernmost part of Extremadura (Spain). The description of the new variety is given below.

\section{Serapias strictiflora var. elsae (Delforge) C. Venhuis \& P. Venhuis, comb. et stat. nov. Fig. 5A, B}

Description: Plants with 2-3, subglobose or ovoid tubercules. Stem straight and cylindrical, 100-300 mm high, green and often spotted red. Leaves linear-lanceolate, 4-7, 3-5 basalleaves $40-160 \mathrm{~mm}$ long and $6-14 \mathrm{~mm}$ broad, and 1-2 bract-like cauline leaves above. Inflorescence lax, bearing 2-7 slender flowers. Bracts oval-lanceolate, grey to red with reddish veins, $25-50 \mathrm{~mm}$ long and $10-18 \mathrm{~mm}$ wide, normally shorter than the hood. Sepals and petals form a pointed hood, which is normally (sub-)horizontally positioned. Sepals ovallanceolate, $15-25 \mathrm{~mm}$ long, green to red coloured with pinkish to purple veins. Petals usually $3 \mathrm{~mm}$ shorter than sepals, from a purple, orbicular base acuminate into a slender, tapering, green to red apical part. Labellum by a constriction divided into hypochile and epichile. Hypochile $0.8-1.2 \mathrm{~cm}$ long and $1.1-1.7 \mathrm{~cm}$ wide. Lateral lobes hidden inside, or slightly emerging from the hood, purple with a pink to red coloured centre. Hypochile with a deeply grooved stigmatic surface, deep purple. Epichile lanceolate, 12-20 mm long and (5-) 6-10 mm wide, yellowish, pinkish, bright red to purple and very short yellowish to reddish hairs. Ovary cylindrical, $10-25 \mathrm{~mm}$.

$S$. vomeracea group. $S$. cordigera and $S$. neglecta. Serapias cordigera and S. neglecta are morphologically rather similar (Figs. 2a, b, $3 b)$. They nevertheless have clear discriminating characters. Serapias neglecta is distinguished from $S$. cordigera by its low stature, lateral hypochile lobes that far exceed the hood and a salmon-pink flower colour, and can therefore be regarded as a different species.

Serapias cordigera is normally an obligate outcrosser (Perez Chiscano et al. 1991, Baumann and Baumann 1999). Like Tyteca (1997), we observed that flowers of S. cordigera from the Algarve are predominantly self-pollinated and even cleistogamous, and that some specimens are (semi-)hypochromatic. Plants with pale hypochromatic flowers from this region had already been given names such as $S$. cordigera var. leucantha Guimarães and $S$. cordigera var. leucoglottis Welwitsch, S. nurrica Corrias and $S$. viridis Perez Chiscano (Guimarães (1887), Wallenwein and Breier (1992), Salkowski (1993), Kreutz (1995) and Tyteca (1997)). Plants from the studied population from the Algarve (Cotifo) had slightly smaller flowers than individuals of $S$. cordigera from Extremadura and southern France. The flowers of $S$. cordigera from Cotifo were all redpurple but several specimens had white lines along the margins of the epichile (thus resem- 


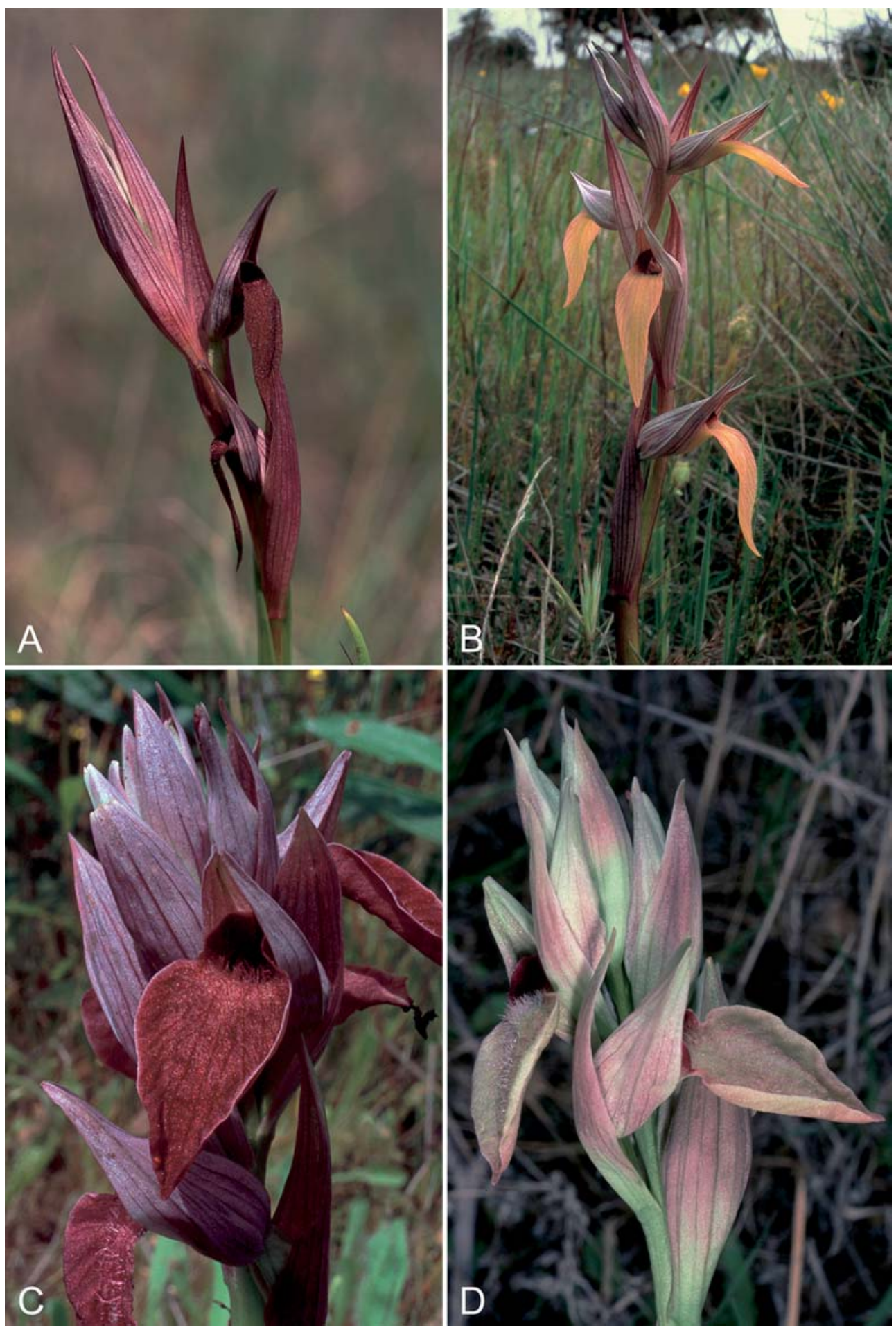

Fig. 5. A S. strictiflora var. elsae, Barão de São Miguel, Algarve, 15-04-2005; B S. strictiflora var. elsae, Cabrela, Alentejo, 11-04-2004; C S. cordigera subsp. gentilii, Cotifo, Algarve, 16-04-2005; D S. cordigera subsp. gentilii, Barranco do Velho, Algarve, 09-04-1994. The taxon names given here are those proposed in this paper on the basis of our analyses. Photographs A-C by C. Venhuis, D by C. A. J. Kreutz 
bling $S$. nurrica, a species we did not study). Our observations showed that the pollinia of $S$. cordigera from the Algarve were pulverulent, quickly disintegrating onto the stigmatic surface. Tyteca (1997) concluded that flowers of $S$. cordigera from the Algarve were similar to those of $S$. perez-chiscanoi as described by Keitel (1991). Given the small flower size of the latter species, this implies that the $S$. cordigera flowers measured by Tyteca were smaller than those measured by us. Though only a small percentage of the flowers were green, yellow, pink or white-lined, they differed in more aspects from "normal" S. cordigera.

Our morphometric analyses, combined with observations of Perez Lara (1886) and Tyteca (1997), showed that plants in the Algarve populations had slightly smaller flowers with a less heart-shaped epichile than those from the remainder of its distribution area. Baumann and Baumann (1999) described a coastal subsp. cretica of $S$. cordigera that also has a slender epichile, but these plants were cross-pollinated and purple. The population of $S$. cordigera from the Algarve is, nevertheless, clearly a member of the $S$. cordigera cluster. On the basis of its morphometric discrimination, a disjunct distribution, deviant reproductive behaviour, and to prevent confusion with respect to the multiple names that exist for specimens of $S$. cordigera from the coastal regions of the Algarve and southwest Spain, we propose to rename this taxon $S$. cordigera subsp. gentilii.

Serapias cordigera subsp. gentilii C. Venhuis, $P$. Venhuis \& Kreutz subsp. nov. Holotypus: Portugal, Algarve, Cotifo, 24-04-06. C. Venhuis \& J. G. B. Oostermeijer (AMD123443). Dedicated to Antonio Gentil Cabrilla; contemporary Spanish biologist working for the nature conservation organization ADENEX. Fig. 5C, D.

Description: Plants with 2 subglobose or ovoid pseudotubercules. Stem straight and cylindrical, 100-260 mm high, green and often spotted red. Leaves linear-lanceolate, 5-11: 4-8 basal- leaves $80-150 \mathrm{~mm}$ long and $7-16 \mathrm{~mm}$ broad, and 1-3 bract-like cauline leaves above. Inflorescence dense, with 3-11 large flowers. Bracts oval-lanceolate, green to grey-lilac with greenish to reddish veins, $26-47 \mathrm{~mm}$ long and 13- $20 \mathrm{~mm}$ wide, normally shorter than the hood. Sepals and petals form a pointed hood, which is normally (sub-)horizontally positioned. Sepals oval-lanceolate, $18-26 \mathrm{~mm}$ long, green to grey-lilac coloured with greenish to purple veins. Petals usually $3 \mathrm{~mm}$ shorter than sepals, from a pink to purple, orbicular base acuminate into a slender, tapering, green to red apical part. Labellum divided by a constriction into a hypo- and epichile. Hypochile 9-13 mm long and 16-24 mm wide. Lateral lobes hidden inside, or slightly emerging from, the hood, red to purple with a pink to red-coloured centre with two diverging lamellae, deep purple. Epichile slightly heartshaped, often with divergent edges, 15-24 mm long and 13-20 mm wide, yellowish, pinkish to purple and with large yellowish to reddish hairs. Ovary cylindrical, 10-20 mm.

$S$. vomeracea subsp. vomeracea and $S$. occidentalis. Serapias vomeracea is distributed across most of the European Mediterranean zone (Landwehr 1977; Perez Chiscano et al. 1991; Delforge 1995, 2002) and is commonly divided into three subspecies: $S$. vomeracea subsp. vomeracea, $S$. vomeracea subsp. longipetala (Tenore) Baumann \& Künkele and $S$. vomeracea subsp. istriaca (Perko) Kreutz. Serapias vomeracea subsp. vomeracea probably occurs in the western (Benito Ayuso and Tabuenca Marraco 2001) and central part of the Mediterranean zone (Baumann and Künkele 1989). Serapias vomeracea subsp. longipetala occurs further eastwards, from Italy to Greece (Baumann and Künkele 1989), and S. vomeracea subsp. istriaca occurs in Istria (Delforge 2002). Benito Ayuso and Tabuenca Marraco (2001) suggested that individuals on photographs of $S$. vomeracea subsp. vomeracea, shown for populations in Extremadura by Pérez Chiscano et al. (1991) to some extent differ from $S$. vomeracea from the northeastern part of Spain. Confusion further 
increases by the fact that Tyteca (1997), Kreutz (pers. comm., 2004), Benito Ayuso (pers. comm., 2004) and Venhuis et al. (2004) postulated that the individuals depicted on these photos display morphological similarities with $S$. cordigera, which occurs on the entire Iberian Peninsula (Landwehr 1977). On the basis of morphological data, Venhuis et al. (2006) concluded that the putative $S$. vomeracea from Extremadura probably originated from hybridisation between $S$. vomeracea subsp. vomeracea and $S$. cordigera and described this taxon as a new species: $S$. occidentalis. Our discriminant analyses show that function 1 distinguishes $S$. occidentalis from $S$. vomeracea subsp. vomeracea (Fig. $3 b$ ). This discriminant function demonstrates that $S$. occidentalis has a significantly longer and wider hypochile. Function 2 distinguishes $S$. occidentalis from $S$. cordigera on the basis of a smaller epichile and a relatively lax inflorescence. For the first and third discriminant functions, $S$. occidentalis clusters with $S$. cordigera (Fig. 3c) which is distinguished from S. vomeracea subsp. vomeracea on the basis of taller plants and a larger sepal size. In contrast with $S$. cordigera, which has two divergent lamellae, S. occidentalis is characterised by two more or less parallel lamellae that are positioned closely together. On the basis of morphometric- and phylogenetic data, S. occidentalis is thus intermediate between $S$. vomeracea subsp. vomeracea and $S$. cordigera. This could indeed indicate a hybrid origin.

S. perez-chiscanoi. Most authors describe S. perez-chiscanoi as a close relative of $S$. vomeracea (Perez Chiscano 1988; Baumann and Künkele 1989; Perez Chiscano et al. 1991; Delforge 1995, 2002). It seems, however, that $S$. vomeracea does not occur in southwest Spain and Portugal (Benito Ayuso and Tabuenca Maracco 2001, Venhuis et al. 2004). The absence from southern Spain and Portugal of $S$. vomeracea does not necessary imply that $S$. perez-chiscanoi could not be closely related to $S$. vomeracea, as it could have speciated allopatrically. Kreutz (1995) described yellow-flowered Serapias plants from the Algarve (Portugal) and concluded, like Jansen (1993), that they were different from $S$. perez-chiscanoi in Extremadura. His assumption was based on the yellow colour of the flowers, the intensely red epichile, the pinkish bracts, sepals and petals, and a different growth habitat to that of $S$. perez-chiscanoi in Extremadura. Tyteca (1997) argued that " $S$. perez-chiscanoi" plants from Extremadura, as well as the $S$. cordigera plants from the Algarve, represent degenerate forms of $S$. cordigera, and so at most merit the status of form or variety. Based on our morphological analyses on material from Extremadura, we agree that $S$. perez-chiscanoi resembles $S$. cordigera, but consider it to be a distinct species for the following reasons: (1) discriminant analyses (Figs. 2a, 3b, c) showed that $S$. perez-chiscanoi is morphologically clearly separated from all other species; (2) S. perezchiscanoi has separate, parallel lamellae, contrasting with the divergent lamellae of $S$. cordigera; (3) S. perez-chiscanoi is autonomously self-pollinating, whereas $S$. cordigera is generally an obligate outcrosser (Delforge 1995, 2002); (4) in the field we observed that the habitat of $S$. perez-chiscanoi is different from that of S. cordigera. S. perez-chiscanoi seems to prefer water-retaining soils in depressions, whereas $S$. cordigera occurs on drier slopes. Additionally, we never observed both taxa cooccurring at the same site. Finally, flower colour differs considerably between the two taxa, although this is not necessary a relevant character because hypochromatic individuals occur in many Serapias species found in Spain and Portugal. Several of the above-mentioned characters are also applicable to $S$. cordigera subsp. gentilii. It may be that this small and often pale-flowered taxon is characterised by a selfing breeding system, as some taxa from other orchid genera (Catling 1990) also show this tendency.

We thank José Luis Pérez Chiscano, Rob Poot, Karel Kreutz, Helmut Presser, Olivier Gerbaud, Noel Kerremans, Kees Jager, Rien Schot and Frank Verhart for their kind help in providing 
localities of the species. Francisco María Vázquez Pardo is gratefully acknowledged for his assistance in providing literature from the past 150 years about the genus Serapias in Spain.

\section{References}

Aceto S., Caputo P., Cozzolino S., Gaudio L., Moretti A. (1999) Phylogeny and evolution of Orchis and allied genera based on ITS DNA variation: morphological gaps and molecular continuity. Molec. Phylogenet. Evol. 13: 67-76.

Bateman R. M., Hollingsworth P. M., Preston J., Luo Y.-B., Pridgeon A. M., Chase M. W. (2003) Molecular phylogenetics and evolution of Orchidinae and selected Habenariinae (Orchidaceae). Bot. J. Linn. Soc. 142: 1-40.

Bateman R. M., Pridgeon A. M., Chase M. W. (1997) Phylogenetics of subtribe Orchidinae (Orchidoideae, Orchidaceae) based on nuclear ITS sequences. 2. Infrageneric relationships and reclassification to achieve monophyly of Orchis sensu stricto. Lindleyana 12: 113-141.

Baumann B., Baumann H. (1999) Ein Beitrag zur Kenntnis der Serapias cordigera-Gruppe (A contribution to the knowledge of the Serapias cordigera group). J. Eur. Orch. 31: 495-521.

Baumann H., Künkele S. (1989) Die Gattung Serapias L. Eine taxonomische Übersicht. Mitt. Bl. Arbeitskr. Heim. Orch. Baden-Württ. 21: 701-946.

Benito Ayuso J., Tabuenca Marraco J. M. (2001) Apuntas sobre orquídeas Ibéricas. Estud. Mus. Cienc. Nat. Alava 16: 67-87.

Catling P. M. (1990) Auto-pollination in the Orchidaceae. In: Arditti J. (ed.) Orchid biology, reviews and perspectives.V. Timber Press, Oregon, pp. 121-158.

Delforge P. (1995) Orchids of Britain \& Europe. Harper Collins Publishers, London, UK.

Delforge P. (2002) Guía de las Orquídeas de España y Europa. Lynx Ediciones, Barcelona, Spain.

Delforge P. (2004) Le Sérapias d'Elsa. Nat. Belg. 85: 103-109.

D'Emerico S., Galasso I., Pignone D. (1998) Karyomorphological considerations on some taxa of the genus Serapias L. (Orchidaceae). Inf. Bot. Ital. 29: 311.

Gölz P., Reinhard H. R. (1980) Serapias (Orchidaceae) Ergebnisse statistischer und chorologischer Untersuchungen. Mitt. B1. Arbeitskr. Heim. Orch. Baden-Württ. 12: 123-189.
Gravendeel B., Vogel E. F. de (2002) Revision of Coelogyne section Moniliformes (Orchidaceae) based on morphology, plastid and nrDNA ITS sequences. Blumea 47: 409-462.

Guimarães J. (1887) Orchideographia portugueza. Bol. Soc. Broteriana 5: 17-84.

Jansen H. (1993) Serapias viridis Perez Chiscanoi in Portugal. Mitt. Bl. Arbeitskr. Heim. Orch. Baden-Württ. 10: 50-53.

Keitel C. (1991) Serapias viridis Perez Chiscano, Dactylorhiza maculata ssp. caramulensis Vemeul. und andere interessante spanische Orchideenarten. Mitt. Bl. Arbeitskr. Heim. Orch. BadenWürtt. 23: 107-121.

Kreutz C. A. J. (1995) Enkele groeiplaatsen van Serapias in Portugal en Spanje. Eurorchis 7: 9096.

Kreutz C. A. J. (2004) Catalogue of European Orchids. Kreutz Publishers, Landgraaf: p. 239.

Landwehr J. (1977) Wilde Orchideeën van Europa. Vereniging tot Behoud van Natuurmonumenten in Nederland, deel I + II: p. 575.

Maire A., Stephenson T. (1930) Sur quelque plantes nouvelles ou peu connues de l'Algérie orientale. Bull. Soc. Hist. Nat. Afr. Nord 21: 48-50.

Maire R. C. J. E., Weiller M. (1959) Flore de l'Afrigue du Nord 6. Lechevalier, Paris, pp. 317319.

Martine P., Gerbaud O. (1998) Considérations sur quelques Serapias varois. L'Orchidophile 130: 10-22.

Pellegrino G., Cafasso D., Widmer A., Soliva M., Musacchio A., Cozzolino S. (2001) Isolation and characterization of microsatellite loci from the orchid Serapias vomeracea (Orchidaceae) and cross-priming to other Serapias species. Molec. Ecol. Notes 4: 279-280.

Perez Chiscano J. L. (1988) Nueva especie de Serapias L. en Extremadura (Espana). Homenaje a Pedro Montserrat, Jaca y Huesca: 305-309.

Perez Chiscano J. L., Gil Llano J. R., Duran Oliva F. (1991) Orquídeas de Extremadura. Fonda Natural, Madrid, p. 223.

Pérez Lara J. M. (1886) Florula gaditana. Pars prima. An. R. Soc. Esp. Hist. Nat. 1: 349-475.

Pridgeon A. M., Bateman R. M., Cox A. V., Hapeman J. R., Chase M. W. (1997) Phylogenetics of subtribe Orchidinae (Orchidoineae, Orchidaceae) based on nuclear ITS sequences. 1. Intergeneric relationships and polyphyly of Orchis sensu lato. Lindleyana 12: 89-109. 
Salkowski H. E. (1993) Serapias nurrica Corrias in der Provinz Algarve/Südportugal. Mitt. Bl. Arbeitskr. Heim. Orch. Baden-Württ. 10: 28-29.

Schlechter R. (1923) Mitteilungen über europäische und mediterrane Orchideen. In: Fedde F. Repertorium Europaeum et Mediterraneum 36: 561-573.

Sundermann H. (1980) Europäische und Mediterrane Orchideen. 3rd ed. Brücke-Verlag Kurt Schmersow, Hildesheim.

Tyteca D. (1997) The orchid flora of Portugal. Jour. Eur. Orch. 29: 267-271, 356-359.

Venhuis C., Venhuis P., Ellis-Adam A. C. (2006) A new Tongue-orchid (Orchidaceae) in southwest Spain: Serapias occidentalis. Anales Jard. Bot. Madrid. 63: 131-143.

Venhuis C., Oostermeijer J. G. B., Tonk J. Th. P. (2004) Conservation biology of Serapias perez-chiscanoi Acedo in the Guadiana river basin in Extremadura (Spain). Eurorchis 16: 48-63.

Wallenwein F., Breier W. (1992) Bemerkungen zu einigen Arten der Gattung Serapias L. aus Spanien. Mitt. Bl. Arbeitskr. Heim. Orch. Baden-Württ. 24: 115-120.

Address of the authors: C. Venhuis, P. Venhuis, J. G. B. Oostermeijer (e-mail: oostermeijer@science. uva.nl), and P. H. van Tienderen, Institute for Biodiversity and Ecosystem Dynamics, Universiteit van Amsterdam, Kruislaan 318, 1098 SM, Amsterdam, The Netherlands. 